[Agr. Biol. Chem., Vol. 32, No. 10, p. 1292 1298, 1968]

\title{
Studies on the Biosynthesis of Blasticidin S
}

\section{Part I. Precursors of Blasticidin S Biosynthesis}

\author{
By Haruo Seto, Isamu Yamaguchi, ${ }^{*}$ Noboru Ötake \\ and Hiroshi Yonehara \\ Institute of Applied Microbiology, The University of Tokyo, Tokyo \\ Received June 14, 1968
}

\begin{abstract}
Biosynthesis of blasticidin S by the producing organism Streptomyces griseochromogenes has been investigated with the use of ${ }^{14} \mathrm{C}$-labeled compounds. Studies on the incorporation of the labeled compounds demonstrated that blasticidin $\mathrm{S}$ was biosynthesized from Dglucose, cytosine, L-arginine and L-methionine as precursors.
\end{abstract}

Blasticidins $(\mathrm{I})^{\mathbf{5 1})}$ is an antibiotic produced by Streptomyces griseochromogenes and the structure has been elucidated including the absolute configuration as shown in formula 1 .

It consists of a pyrimidine nucleoside designated cytosinine (III) and a $\beta$-amino acid, blastidic acid (III) as structural components.
From the biosynthetic point of view, I is a compound of particular interest, since it contains a peculiar nucleoside II and an unusual $\beta$-amino acid III.

Hitherto, several paper have reported on the biosynthesis of nucleosidic antibiotics such as angustmycin $\mathrm{A}$ (decoyinine) ${ }^{6)}$ and angustmycin<smiles>CN(CCCC(N)CC(=O)NC1C2C3C1C23n1ccc(N)nc1=O)C(=N)N</smiles>

(I)<smiles>CN(CCC(N)CC(=O)O)C(=N)N</smiles>

(II)

(III)

* Present adress: The Institute of Physical and Chemical Research 2-28-8, Honkomagome, Bunkyoku, Tokyo, Japan.

1) N. Ötake, S. Takeuchi, T. Endō and $H$. Yonehara Tetrahedron Letters, 1965, 1405.

2) N. Ötake, S. Takeuchi, T. Endō and $H$. Yonehara, ibid., 1965, 1411.

3) N. Ötake, S. Takeuchi, T. Endō and H. Yonehara, Agr. Biol. Chem., 30, 126 (1966).

4) N. Ötake, S. Takeuchi, T. Endō and $H$. Yonehara, ibid., 30, 132 (1966).

5) H. Yonehara and N. Otake, Tetrahedron Letters, 1966, 3785.
C (psicofuranine), ${ }^{71}$ however, these studies were related to the biosynthesis of the purine nucleosides, therefore, the analogous mechanisms could not be regarded to be operating in the case of a pyrimidine nucloside. Although, the biosynthetic mechanisms of

6) B. M. Chassy, T. Sugimori and R. J. Suhadolnik, Biochim. Biophy. Acta, 130, 12 (1966).

7) T. Sugimori and R. J. Suhadolnik, J. Am. Chem, Soc., 87, 1136 (1965). 
cytidine formation were well established, its structure is entirely different from II. Furthermore, III may be called $\delta$-N-methyl- $\beta$ arginine, a $\beta$-amino acid found for the first time in the natural product field, so the studies of its origin seem significant.

A preliminary communication of this work has been published in a previous paper, ${ }^{81}$ and this report concerns the details of the experiments using ${ }^{14} \mathrm{C}$-labeled compounds to account for the biosynthetic aspects of I.

\section{MATERIALS AND METHODS}

\section{Medium and cultures}

An improved strain of Streptomyces griseochromogenes No. 1 was used through these studies.

Medium-1. The seed medium contained molasses $1 \mathrm{~g}$, starch $1 \mathrm{~g}$, meat extract $1 \mathrm{~g}$ and peptone $1 \mathrm{~g}$ in $100 \mathrm{ml}$ of distilled water and the $\mathrm{pH}$ was adjusted to 7.2 before sterilization. The cultural medium was inoculated and incubated at $30^{\circ} \mathrm{C}$ on a reciprocal shaker for $48 \mathrm{hr}$ and was used as an inoculum for Medium-2.

Medium-2. The synthetic medium used for the production of I contained the following: (A) sucrose $100 \mathrm{~g}$ and glucose $5 \mathrm{~g}$ in $800 \mathrm{ml}$ of distilled water; (B) $\left(\mathrm{NH}_{4}\right)_{2} \mathrm{HPO}_{4} 10 \mathrm{~g}$ and $\mathrm{KCl} 3 \mathrm{~g}$ in $100 \mathrm{ml}$ of distilled water; (C) $\mathrm{CaCl}_{2}, 2 \mathrm{H}_{2} \mathrm{O} 3 \mathrm{~g}$ in $50 \mathrm{ml}$ of distilled water; (D) $\mathrm{MgSO}_{4} .7 \mathrm{H}_{2} \mathrm{O} 2 \mathrm{~g}, \mathrm{FeSO}_{4} .7 \mathrm{H}_{2} \mathrm{O} 40 \mathrm{mg}, \mathrm{ZnSO}_{4}$. $7 \mathrm{H}_{2} \mathrm{O} 40 \mathrm{mg}$ in $50 \mathrm{ml}$ of distilled water. Part A, B, $\mathrm{C}$ and $\mathrm{D}$ were sterilized separately and combined after cooling to avoid precipitation of the mineral complex. The $\mathrm{pH}$ of the mixed solution became 6.5.

Medium-3. When ${ }^{14} \mathrm{C}$-glucose was used as precursor, the medium consisted of sucrose $5 \mathrm{~g}$, soybean meal $2 \mathrm{~g}$ and $\mathrm{NaCl} 0.5 \mathrm{~g}$ in $100 \mathrm{ml}$ of distilled water and the $\mathrm{pH}$ was adjusted to 6.5 before sterilization.

\section{Preparation of ${ }^{14} \mathrm{C}$ labeled-I}

A $2 \mathrm{ml}$ of the inoculum described above was introduced into a $500 \mathrm{ml}$ Erlenmyer flask containing $100 \mathrm{ml}$ of medium-2 and incubated on a rotary shaker at $30^{\circ} \mathrm{C}$. After $48 \mathrm{hr}$, the ${ }^{14} \mathrm{C}$-labeled compounds were added aseptically to the cultures and the incubation was continued. The time course of the fermentation is presented in Fig. 1.

The yield of I produced under this condition was evaluated by the microbiological assay of the cylinder-

8) H. Seto, I. Yamaguchi, N. Ōtake and H. Yonehara, Tetrahedron Letters, 1966, 3793.

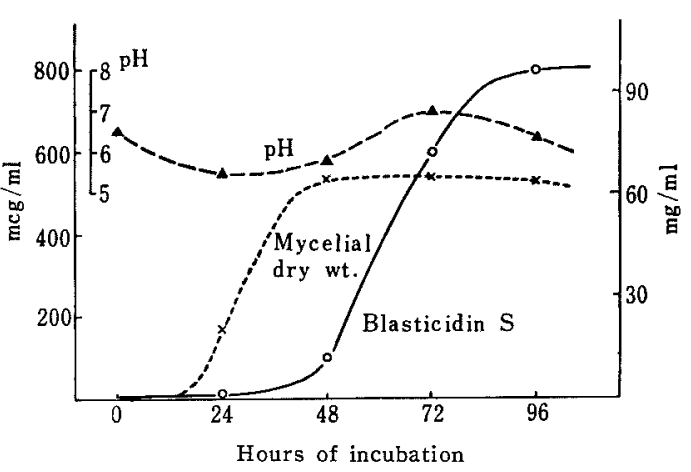

FIG. 1. Fermentation Process of Streptomyces griseochromogenes.

plate agar diffusion method with the use of Bacillus cereus as test organism, ${ }^{9}$ 'Seventy two hours after inoculation, an adequate amount of non-labeled $I$ was added as a carrier and the fermentation broth was filtered. The filtrates were passed through a column of Amberlite IRA-410 (OH- type) and washed successively with distilled water. The effluents and washings were directly adsorbed on a column of Dowex 50W$\mathrm{XI}(\mathrm{H}+$ type) and washed with water successively followed with $5 \%$ pyridine, then the column was eluted with $1.2 \%$ ammoniacal water. Appropriate fractions showing UV absorption and ninhydrin reaction were combined and the solution was evaporated in vacuo as quickly as possible at a bath temperature under $45^{\circ} \mathrm{C}$. The residue was redissolved in a small volume of $\mathrm{CO}_{2}$ free redistilled water and the solution was allowed to stand overnight in a refrigerator to give crystals fo radioactive-I.

Degradation of radioactive-I and isolation of the degradation products

Hydrolysis of $\mathrm{I}$ was carried out in $3 \mathrm{~N}$ sulfuric acid solution at $90^{\circ} \mathrm{C}$ for $48 \mathrm{hr}$ under a continuous flow of nitrogen gas which was free from $\mathrm{CO}_{2}$. The evolved $\mathrm{CO}_{2}$ was caught as $\mathrm{BaCO}_{3}$ by passing through a saturated solution of $\mathrm{Ba}(\mathrm{OH})_{2}$. The precipitated $\mathrm{BaCO}_{3}$ was filtered on a glass filter by suction and washed subsequently with boiled distilled water, ethanol, ether in order and dried under reduced pressure.

After completion of the hydrolysis, the reaction mixture was continuously extracted with ether for $15 \mathrm{hr}$. After dehydration of the ether solution over anhydrous sodium sulfate, ether was removed by

9) H. Iizuka, Agr. Biol. Chem., 29, 77 (1965). 
evaporation under atmospheric pressure to produce a syrup, which was treated with thiosemicarbazide hydrochloride to afford the thiosemicarbazone of levulinic acid.

The aqueous layer from the ether extraction was adjusted to $\mathrm{pH} 6.0$ with $0.5 \mathrm{~N} \mathrm{Ba}(\mathrm{OH})_{2}$ solution and the resultant precipitate of $\mathrm{BaSO}_{4}$ was removed by centrifugation. The supernatant was adsorbed on $a$ column of Amberlite IRA-410 (OH- type) and washed thoroughly with distilled water and the column was eluted with $0.5 \mathrm{~N}$ aqueous $\mathrm{CH}_{3} \mathrm{COOH}$ to afford crystals of II in substantially pure form, which was recrystallized from aqueous acetone. On the other hand, the effluent was fractionated and the appropriate fractions of $\mathrm{pH}$ above 7.5 showing ninhydrin reactions were combined and adsorbed on a column of Amberlite IRC-50 ( $\mathrm{H}^{+}$type). After being washed with distilled water, the column was eluted with $0.5 \mathrm{~N}$ $\mathrm{HCl}$ and the appropriate fractions positive to ninhydrin test were combined and decolorized with activated charcoal. The solution was evaporated in vacuo to afford crystalline needles of III as a dihydrochloride which was recrystallized from hot ethanol.

Finally, the effluents of $\mathrm{pH}$ below 7.5 from the column of Amberlite IRA-410 showing UV absorption were adsorbed on a column of Dowex 50W-X1 $\left(\mathrm{H}^{+}\right.$ type) and washed with distilled water. Then the column was eluted with $5 \%$ pyridine and the eluate was concentrated in vacuo to give crystals of cytosine which were recrystallized from hot water. These degradation products were recrystallized until their specific radioactivity became constant.

\section{Degradation of III}

III was degraded in $0.5 \mathrm{~N} \mathrm{Ba}(\mathrm{OH})_{2}$ solution to

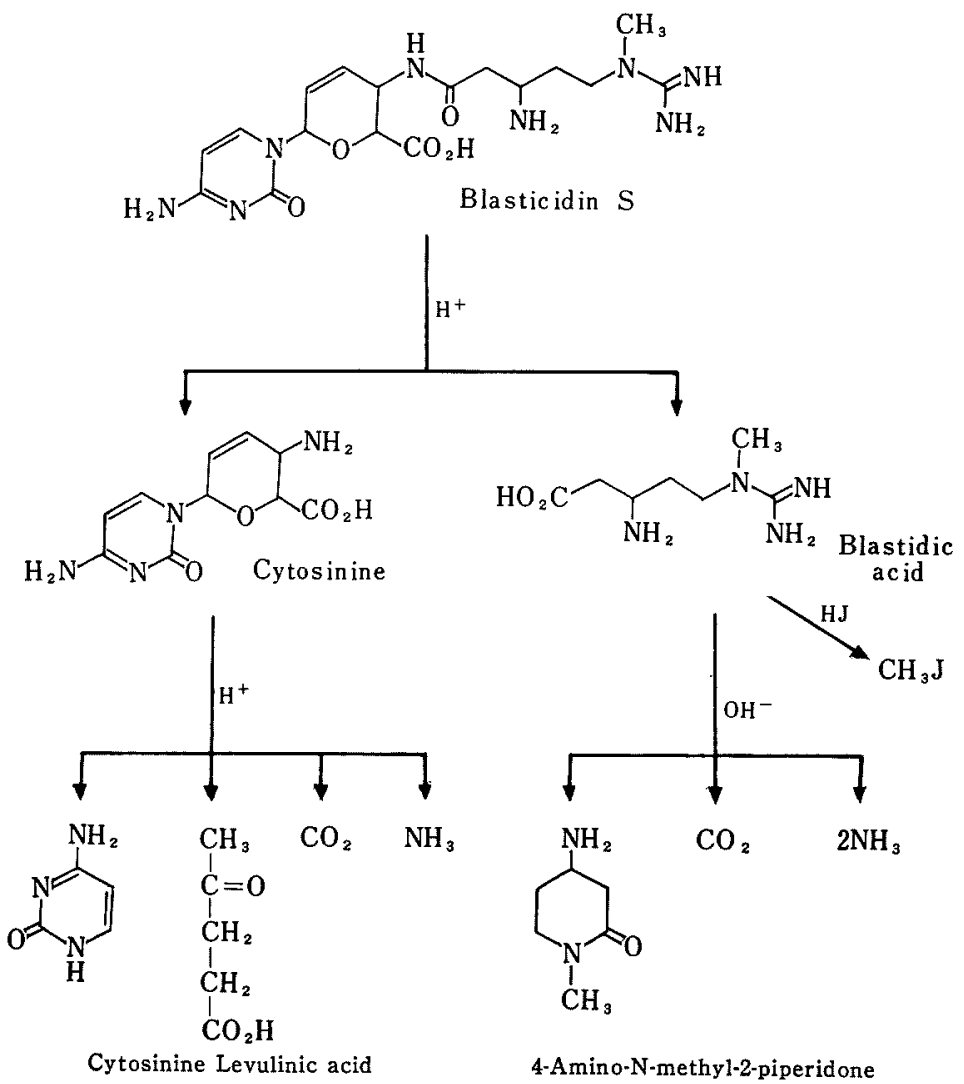

FIG. 2. Degradation Scheme of Radioactive Blasticidin S. 
afford $\mathrm{CO}_{2}$ and 4-amino-N-methyl-2-piperidone ${ }^{10}$ under a stream of $\mathrm{CO}_{2}$ free nitrogen gas. $\mathrm{CO}_{2}$ was precipitated as $\mathrm{BaCO}_{3}$ and purified as mentioned above. 4-Amino-N-methyl-2-piperidone was purified by vacuum distillation. N-Methyl group of III was converted into $\mathrm{CH}_{3} \mathrm{~J}$ by the action of $\mathrm{HJ}$, which was absorbed in toluene and the radioactivity was directly measured by scintillation counting. The degradation scheme of $I$ is summarized in Fig. 2.

\section{Isolation and identification of L-ornithine in the fermentation broths}

A filtered broth of St. griseochromogenes cultured under the same condition was passed through a column of active carbon and washed with distilled water. Effluent and washings were adsorbed on a column of IRA-410 (OH- type). Then the column was eluted with $0.5 \mathrm{~N} \mathrm{CH}_{3} \mathrm{COOH}$ and the eluate was concentrated in vacuo. The residue was dissolved in distilled water and adsorbed on Dowex 50W-Xl ( $\mathrm{H}^{+}$type). The column was washed with $5 \%$ pyridine and then eluted with $1.2 \%$ ammonia. Appropriate fractions positive to ninhydrin test were collected and concentrated to afford a crystalline mass which was applied as a sample for paper chromatographic identification.

\section{Radioactivity measurement}

Radioactivities were measured by a Packard liquid scintillation spectrometer in dioxane-naphthalene solution (naphthalene $1 \mathrm{~g}$, PPO $100 \mathrm{mg}$ and POPOP $2.5 \mathrm{mg}$ in $10 \mathrm{ml}$ dioxane). $\mathrm{BaCO}_{3}$ was suspended in toluene scintillation solution (PPO $40 \mathrm{mg}$ and POPOP $1 \mathrm{mg}$ in $10 \mathrm{ml}$ toluene) by the aid of Cab-O-Sil (400 $\mathrm{mg}$ ).

\section{${ }^{14} \mathrm{C}$-Labeled compounds used}

The following ${ }^{14} \mathrm{C}$-labeled compounds were used in this work. D-Glucose-U-14C, D-glucose-1-14C, D-glucose${ }^{6-14} \mathrm{C}$, L-arginine-U-14 $\mathrm{C}$, glycine-U-14 $\mathrm{C}$, L-aspartic acid-
U-14C, L-alanine-U-14C, L-glutamic acid-U-14C and sodium acetate-U-14C (from Daiichi Chemical); Lmethionine-methyl-14 $\mathrm{C}$, cytosine-2-14 $\mathrm{C}$ and cytidine- $\mathrm{U}$ ${ }^{14} \mathrm{C}$ (from Radio Chemical Center); and $\beta$-alanine-3${ }^{14} \mathrm{C}$, (from New England Nuclear).

\section{RESULTS AND DISCUSSION}

Incorporation of various compounds into blasticidin $\mathbf{S}$

The incorporation ratio of ${ }^{14} \mathrm{C}$-labeled compounds into the antibiotic is presented in Table I.

Among the compounds tested, D-glucose-U${ }^{14} \mathrm{C}$, D-glucose- $1-{ }^{14} \mathrm{C}$, D-glucose- $6-{ }^{14} \mathrm{C}$, cytosine$2-{ }^{14} \mathrm{C}$, cytidine-U- $-{ }^{14} \mathrm{C}$, L-methionine-methyl- ${ }^{14} \mathrm{C}$, $\mathrm{L}$-arginine- $\mathrm{U}-{ }^{14} \mathrm{C}$ and $\mathrm{L}$-arginine-guanidino- ${ }^{14} \mathrm{C}$ were incorporated very effectively into $\mathrm{I}$. But other amino acids and fatty acid such as glycine, L-alanine, $\beta$-alanine, L-aspartic acid and acetic acid were essentially not incorporated. The minor incorporation ratio observed in the case of $\mathrm{L}$-arginine-U- ${ }^{14} \mathrm{C}$ as compared with that of L-arginine-guanidino- ${ }^{14} \mathrm{C}$ might be ascribed to the transamidination between labeled arginine and unlabeled ornithine which was produced during fermentation.

\section{Distribution of radioactivity in the degradation products of I}

In order to establish the distribution of radioactivity in the labeled antibiotic, I was degraded according to the scheme as shown in Fig. 2. The results are presented in Table II.

On the basis of these experimental results

TABLE I. INCORPORATION RATIO OF ${ }^{14} \mathrm{C}-$ COMPOUNDS INTO BLASTICIDIN S

$\begin{array}{lccr} & (\%) & & (\%) \\ \text { D-Glucose-(U)-14C } & 3.7 & \text { L-Arginine-(U)-14C } & 30.3 \\ \text { D-Glucose-1-14C } & 4.0 & \text { *L-Aspartic acid-(U)-14C } & 0.5 \\ \text { D-Glucose-6-14C } & 4.9 & \beta \text {-Alanine-1-14C } & 0.6 \\ \text { Cytosine-2-14C } & 95.1 & \text { Acetic acid-(U)-14C } & 0.5 \\ \text { Cytidine-(U)-14C } & 15.3 & \text { Glycine-(U)-14C } & 1.1 \\ \text { L-Methionine-(methyl)-14C } & 38.3 & \text { L-Alanine-(U)-14 C } & 0.5 \\ \text { L-Arginine-(guanidino)-14C } & 51.2 & & \\ \text { * Unlabeled cytosine was added simultaneously. } & \end{array}$

10) T. Endō, N. Ōtake, S. Takeuchi and H. Yonehara, J. Antibiotics, 17A, 172 (1964). 


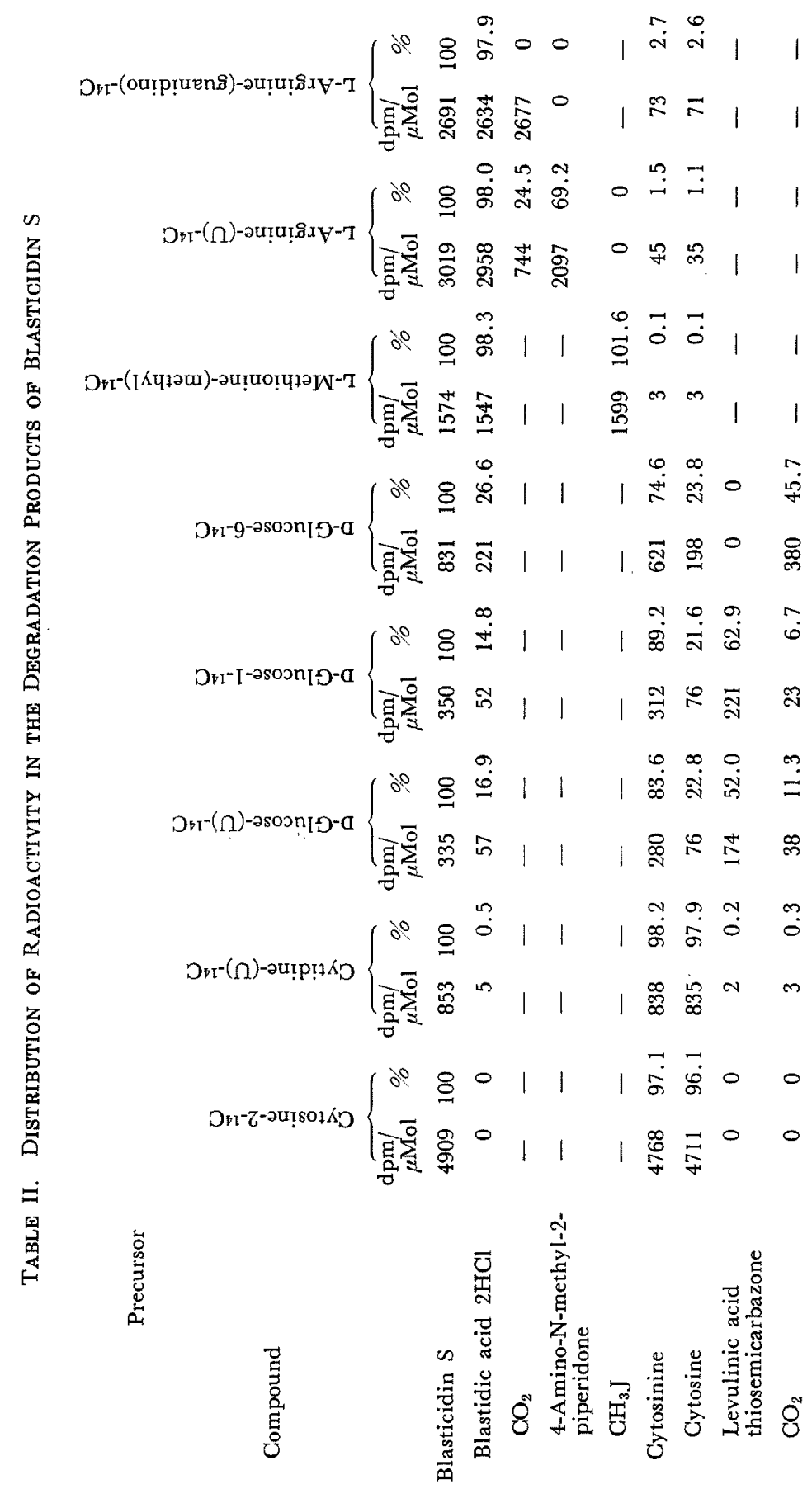


the following conclusions are confirmed:

i) Cytosine is incorporated intact into the cytosine part of I in high yield and randomization does not take place.

ii) When cytidine is supplemented as precursor, almost all of radioactivity locates in the cytosine nucleus of I, but only negligible amounts in the sugar portion, indicating the cleavage occurred in the glycosidic linkage. A similar result was also reported in the case of the biosynthesis of angustmycin C. ${ }^{71}$

iii) When $I$ is labeled with glucose as precursor, most of the radioactivity locates in the sugar portion, but in this case, a considerable randomization is observed. The reason for this remarkable randomization is explicable based on the incorporation of ${ }^{14} \mathrm{C}$-carbamyl phosphate ${ }^{11 /}$ formed from ${ }^{14} \mathrm{C}$-labeled glucose in the course of the fermentation. Indeed, the $\mathrm{C}_{2}$ of cytosine nucleus and guanidino carbon of III are radioactive.

iv) It is of particular interest to consider about the formation of levulinic acid from II, the mechanism involving a disproportion reaction as shown in Fig. 3 has been proposed results presented in Table II show good agreement between the experimental and theoretical values.

v) When methionine-methyl $-{ }^{14} \mathrm{C}$ is used as precursor, almost all of the radioactivity is located in III with negligible amounts in II. Further degradation of III with $\mathrm{HJ}$ demonstrates that the methyl group of III is derived from methyl group of L-methionine.

The introduction of a methyl group into the guanidino nitrogen of III is probably comparable to creatine formation ${ }^{12\}}$ from guanidino acetic acid.

vi) When $I$ is labeled with L-arginineguanidino $-{ }^{14} \mathrm{C}$ as precursor, almost all of the radioactivity is observed in the $\mathrm{CO}_{2}$ derived from the guanidino-carbon of III after the hydrolysis with $\mathrm{Ba}(\mathrm{OH})_{2}$. However, when Larginine- $\mathrm{U}-{ }^{14} \mathrm{C}$ is used as precursor, all of the radioactivity is located in carbon skeleton of III but negligible amounts in $\mathrm{N}$-methyl portion. The radioactivity ratio of 4-amino- $\mathrm{N}$-methyl2-piperidone and $\mathrm{CO}_{2}$ is found to be $3: 1$ experimentally, nevertheless, supposing that $\mathrm{L}$-arginine- $\mathrm{U}-{ }^{14} \mathrm{C}$ is incorporated intact, the

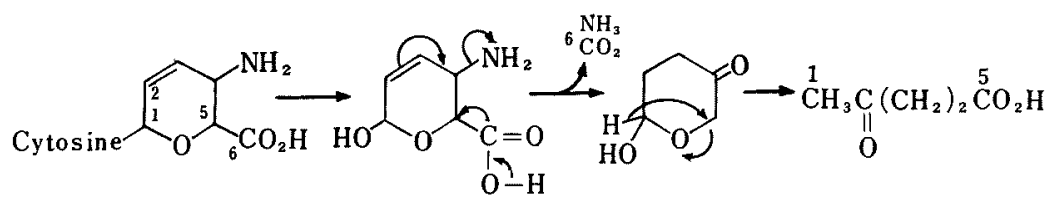

FIG. 3. Mechanism of Levulinic Acid Formation.

by Ōtake et al..$^{31}$ In order to determine the validity of this mechanism, the ratio of levulinic acid and $\mathrm{CO}_{2}$ produced was reinvestigated with the aid of specifically labeled $\mathrm{D}$-glucose as precursor. It could theoretically be expected that, if the randomization in sugar moiety does not take place at all, the ratio of levulinic acid and $\mathrm{CO}_{2}$ must be $5: 1$ with the use of glucose-U- ${ }^{14} \mathrm{C}, 1: 0$ of glucose$1{ }^{14} \mathrm{C}$ and $0: 1$ glucose- $-6-{ }^{14} \mathrm{C}$ respectively. The

11) P. Bernfeld, "Biogenesis of Natural Compounds," Pergamon Press, 1963, p. 56. radioactive ratio must be $5: 1$ as theoretically expected. This deviation of experimental value from theoretical value is ascribable to the transamidination between $\mathrm{L}$-arginine- $\mathrm{U}-{ }^{14} \mathrm{C}$ and L-ornithine produced in the fermentation broth.

Indeed, the presence of a significant dose of radioactive L-ornithine was confirmed in the cultures. The data clearly show that Larginine, except its $\alpha$-amino group, is a direct

12) H. Borsook and J. W. Dubnoff, J. Biol. Chem., 132, 559 (1940). 
precursor of III into which the carbon skeleton may be incorporated intact from L-arginine.

To-date, little information is available concerning the biosynthesis of $\beta$-amino acids, for example, $\beta$-lysine ${ }^{13)}$ and isotyrosine ${ }^{141}$ were reported to be biosynthesized from their corresponding $\alpha$-amino acids, nevertheless, the details of the mechanisms are not certained.

Costilow and his co-workers ${ }^{6 !}$ have reported that with the use of a cell free system of an unidentified strain of Clostridium, $\beta$-lysine was found out to be derived from L-lysine through an interconvertible reaction which needed a catalytic amount of $\alpha$-ketoglutarate or pyridoxal phosphate.

Details of the mechanism which is involved

13) R. N. Costilow, O. M. Rochovansky and H. A. Barker, J. Biol. Chem., 241, 1573 (1966).

14) G. Roncari, Z. Kurylo-Borowska and L. C. Craig, Biochem., 5, 2153 (1966). in the transfer of amino group from $\alpha$ to $\beta$ position remain uncertain, however, one of the possible routes is presumed to be through double bond formation.

In conclusion, the evidence so far presented lends support to a scheme as shown in Fig. 4 depicting the direct incorporation of precursors in blasticidin $\mathrm{S}$ biosynthesis.

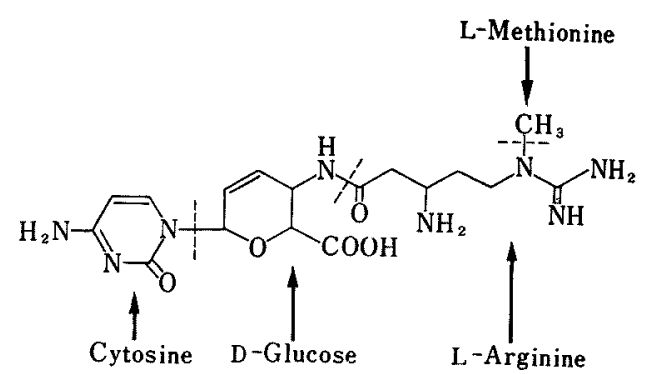

FIG. 4. Precursors of Blasticidin S Biosynthesis. 